\title{
PERFORMANCE Y POPULARIZACIÓN DE UNA VERTIENTE DEL ESPIRITISMO ARGENTINO
}

Gustavo Andrés Ludueña*

Resumen: Este artículo explora y analiza la producción, circulación y consumo de saberes y prácticas espirituales en una vertiente singular del espiritismo argentino. En particular, focalizando el estudio sobre la Escuela Científica Basilio - una organización cuya trayectoria se relaciona históricamente con la doctrina espírita -, este trabajo muestra su rol en la construcción de un espacio socio-religioso que permitió la popularización de conocimientos y prácticas espirituales - principalmente - en sectores subalternos de la sociedad argentina. En suma, se ilustra cómo a través de procesos simbólicos basados en el libre acceso de aquellos segmentos sociales a la literatura institucional, e interpretación y participación en performances rituales, los actores reinventaron el kardecismo clásico para dar origen a una expresión espiritista popular de fuerte base cristiana.

Palabras clave: Espiritismo. Subalternidad. Performance. Sectores populares.

Abstract: This article explores and analyzes the production, circulation and consumption of spiritual knowledge and practices in a singular trend of Argentinean Spiritism. Particularly, by focusing the study on the Escuela Científica Basilio (Basil Scientific School) - an organization with a tradition historically related to the Kardecist doctrine -, this work shows its role in the construction of a religious social space that allowed the popularization of spiritual knowledge and practices mainly - into subaltern sectors of the Argentinean society. To summarize, it is illustrated how symbolic processes based on the free access of those social segments to institutional literature, and interpretation and participation in ritual performances, the actors reinvented classic Kardecism in order to give origin to a popular spiritist expression of strong Christian basis.

Keywords: Spiritism. Subalternity. Performance. Popular sectors.

*Universidad de Buenos Aires. Contato: galuduena@hotmail.com 
Durante la primera mitad del siglo XX, la Argentina estuvo sujeta a cambios profundos que afectaron su economía, política y cultura, así como su constitución social misma. La ciudad capital, Buenos Aires, fue en no poca medida uno de los termómetros que marcaron, grosso modo, la temperatura sociológica de aquellas transformaciones. Entre los procesos que allí tuvieron lugar estuvieron, en primer lugar, la nutrida inmigración de origen europeo y, luego, los acelerados desarrollos de los barrios porteños en los que muchos de esos inmigrantes establecieron sus hogares. Junto a la creciente participación en la política, las asociaciones barriales - e.g., sociedades de fomento, clubes deportivos, bibliotecas, etc. -, y las promesas de movilidad social que parecían presentarse cada vez más sostenidamente a los hijos de los pioneros europeos (De Privitellio, 2003; Gutiérrez y Romero, 2007), la emergencia de nuevas religiosidades en el aún embrionario campo religioso argentino formaría parte de la cultura de los dinámicos sectores populares urbanos. Aquí nos referiremos a ellos como sujetos históricos que, al decir de Luis Alberto Romero, "no son [...] sino que están siendo" (Gutiérrez y Romero, 2007, p. 39). En otras palabras, "los sectores populares no son un sujeto histórico, pero sí un área de la sociedad donde se constituyen sujetos" (Gutiérrez y Romero, 2007, p. 41).

En este horizonte cambiante, personajes sociales como místicos, sanadores, visionarios y religiosos - por ejemplo, Francisco "Pancho" Sierra (1831-1891); María Salomé Loredo y Otaola de Subiza (1855-1928), más conocida como la “Madre María” (LEONE, 1992); Benjamín Solari Parravicini (1884-1974); etc. -, tanto como incipientes instituciones de igual género - entre ellas, centros espiritistas kardecistas (BIANCHI, 1992, 2004; DI RISIO e IRAZABAL, 2003b; OLMOS, 2003); Escuela Magnético-Espiritual de la Comuna Universal; Sociedad Teosófica; Orden Rosacruz AMORC (CERIANI CERNADAS, 2003); y la Escuela Científica Basilio de cuño espiritista (BIANCHI, 2004; DI RISIO e IRAZABAL, 2003a; LUDUEÑA, 2001a, 2001b, 2003, 2007a, en prensa) experimentaron una suerte de crecimiento que los hizo acreedores de cierta popularidad en determinados sectores de la sociedad. Entre estos grupos cabe mencionar a la Orden Martinista, Escuela Raumsólica de Logosofía y, por supuesto, la irrupción pentecostal, como - desde otro ángulo - las religiosidades ligadas al "mundo protestante", "mundo judío" y las llamadas "turcas" que comprendían a las iglesias maronitas, ortodoxas, drusos y musulmanes (BIANCHI, 2004). Todas estas 
agrupaciones hicieron del campo religioso uno que sería sustancialmente heterogéneo para siempre, aunque, por cierto, organizado sobre la base de una estructuración de hegemonías y contrahege-monías con las que recurrentemente entrarían en pugna (LUDUEÑA, 2005).

Sin embargo, no todas esas expresiones fueron patrimonio exclusivo de los sectores populares sino que, de igual modo, representantes de las elites también hallaron espacios para canalizar sus propias inquietudes. Sin pretender agotar este amplio y poco explorado tópico de investigación antropológica e histórica, este artículo aborda la cuestión de los principales mecanismos de popularización de algunas de ellas; en particular, de la Escuela Científica Basilio. Entendemos aquí el término de popularizaciónno sólo en materia de difusión sobre esferas específicas de la estructura social de Buenos Aires, sino de las apropiaciones singulares realizadas por parte de - aunque no únicamente - sectores subalternos. No menos importante aún fue el hecho de que aquellos grupos gozaron de rasgos diferentes y tuvieron, por lo tanto, recepciones diferenciales. Por esta razón, podemos afirmar con Susana Bianchi que "[n]o hay ni culturas ni religiones paradigmáticamente unidas a clases 'enteras' específicas” (2004, p. 150). Aunque muy probablemente sí, sectores cuyos imaginarios y sensibilidades o, más exactamente, estructuras de sentimiento (WILLIAMS, 1980), favorecen en mayor medida la proximidad con unas más que con otras. En este estudio veremos cómo la performanceritual operó, tanto a nivel del cuerpo como del self, como dispositivo microsociológico - con claras consecuencias macrosociales - de construcción y puesta en escena de lo popularen el caso de una vertiente del espiritismo. Comenzaremos, entonces, por establecer brevemente el lugar de este actor social en la sociedad porteña de aquel período.

\section{EL ESPIRITISMO EN ARGENTINA}

\section{ORÍGENES HUMILDES Y CATOLICISMO}

La Escuela Científica Basilio es una institución religiosa de presencia histórica en el país. En los comienzos cultivó un hondo vínculo doctrinal con 
el espiritismo de Allan Kardec (1804-1869). No obstante, aun cuando la fundación en 1917 fue posterior al surgimiento del kardecismo en Argentina, no desarrolló vínculos orgánicos con la Confederación Espiritista ni con los otros círculos espíritas. Esta última organización había surgido en 1900 con el intento de unificar a los centros de aquella adscripción que hacían aparición a fines del siglo XIX. Su historia estuvo, desde los inicios, vinculada a los sectores económicos más rezagados. Los fundadores, Blanca Aubreton de Lambert (1867-1920) y Bernardo Eugenio Portal (1867-1927), fueron inmigrantes franceses ligados a segmentos asalariados y pequeños cuentapropistas (Escuela Científica Basilio, 1967, 1997). En este orden, el período comprendido entre fines del siglo XIX y principios del XX se caracterizó por una significativa inmigración europea que influyó, entre otras cosas, sobre la evolución del espiritismo y otras religiosidades nacientes. En torno a aquellos fundadores se agrupó un pequeño puñado de personas que, al estilo de una communitasespontánea o existencial - para citar la clasificación sugerida por Víctor W. Turner (1988) -, compartían el interés por experiencias concretas de lo numinoso. Los integrantes se conocían, solían pertenecer al mismo barrio, se cruzaban en las calles, eran vecinos... En suma, mantenían una sociabilidad de proximidad - i.e., relaciones sociales cara-a-cara - atravesada por una idéntica adscripción religiosa.

La institución fue centro del avance de, según entenderemos, una suerte de espiritismo popular de cierta celebridad en el cambiante orden citadino. Veremos que este espiritismo sui generis ostentó su popularidad en un doble significado cuantitativo y cualitativo. En el primer caso por la cantidad de miembros activos y adherentes en general a nivel nacional, principalmente, a partir de 1950 y hasta 1980. En segundo lugar, por la procedencia social de los adeptos que, en su mayoría, se incorporaban de sectores medios y bajos de la sociedad; ello sin ignorar la simpatía que despertaban en otros más acomodados, de cuyas sensibilidades e inquietudes parecía presentarse como un óptimo vehiculizador. Como lo señaló Néstor García Canclini (1992, p. 204), "lo popular no es monopolio de los sectores populares."

De un acelerado progreso entre las décadas de 1940 y 1960, el cual se reflejó en un incremento exponencial de afiliados, experimentó luego una estabilización e, incluso, una reducción. Dentro de las expresiones vernáculas de 
espiritismos fue la que tuvo el crecimiento más prominente y, por otro lado, la relación más conflictiva con el catolicismo, aunque ello no lo fue tanto en términos simbólicos. En este contexto, desde sus inicios mostró elementos que la relacionaron directamente con el imaginario católico. De este modo, procedentes de países con catolicismos consolidados como España e Italia (DI STEFANO y ZANATTA, 2000), varios de sus integrantes ya estaban habituados con aquella matriz religiosa. No obstante, muchos de sus principios como el difundido "Jesús no es Dios" (CAIMARI, 1995; Forni, 1993) - resultaron radicalmente opuestos a dogmas teológicos fundamentales.

En esta dirección, verdades aceptadas y defendidas celosamente por la Iglesia como la divinidad de Jesús y la virginidad de María se cuestionaron, en ocasiones, en multitudinarios reuniones públicas. En la doctrina Basilio, Jesús era ahora resignificado como un espíritu de luz, ${ }^{1}$ el cual se había encarnado en la tierra con la misión de redimir a la humanidad para traer conocimientos acerca del mundo espiritual. Al igual que muchos otros - e.g., Buda, Moisés, Krishna, etc. -, Jesús llegaba en calidad de enviado, lo cual reafirmaba su cualidad de Mesías tal como era definido en la tradición judeocristiana. El aspecto más importante, que se opuso más férreamente a la noción cristológica fue, tal como dijimos, la que sostenía que Jesús no era Dios. ${ }^{2}$ Para el espiritismo Basilio, Jesús no era más que cualquiera de los otros hijos del Creador; tal como lo eran el resto de los seres humanos. Tanto su propia divinización como la de María fueron rechazadas sin más (ESCUELA CIENTÍFICA BASILIO, 1997, p. 11). Como resultado, adquirió aquí relevancia la figura de José, considerablemente disminuida en la cosmología católica.

${ }^{1}$ Los "espíritus de luz" son aquellos que nunca se alejaron de Dios, y forman con los que atravesaron la reparación de sus equivocaciones el Bien. Por el contrario, los espíritus que se alejaron dieron nacimiento al mundo del Errory son denominados "espíritus equivocados" (LUDUEÑA, 2001a, en prensa).

2 Las conferencias públicas de la institución durante la década de 1950, publicitadas bajo el eslogan “Jesús no es Dios", provocaron notables enfrentamientos con sectores militantes del catolicismo (CAIMARI, 1995, FORNI, 1993). Tales disputas parecen haberse originado menos por cuestiones de definición teológica que por el respaldo que el espiritismo comenzaba a obtener por parte del gobierno peronista (1946-1955). De hecho, "[e]l espiritismo fue la primera práctica 'disidente' que recibió un apoyo oficial [...] que inquietó a los católicos” (CAIMARI, 1995, p. 202). 
Además, otros aspectos también abrevaron en ese imaginario y terminaron siendo resignificados. Las celebraciones anuales son paradigmáticas en este caso. Estas son las siguientes: Venerable José (19 de marzo), viernes de la Redención (coincidente con Pascua), Venerable María (15 de agosto), Venerable Blanca y Eugenio (25 de junio y 3 de julio), fiesta a Dios (1 de noviembre), Natividad (25 de diciembre) y Venerable Basilio (29 de diciembre). ${ }^{3}$ Estos recordatorios instituyeron una cronología litúrgica donde figuras prominentes de la institución y del ideario católico son anualmente homenajeadas. Por otra parte, los inmigrantes que involucró adscribían en su mayoría a una matriz católica que la Escuela Basilio no hizo más que enfatizar, dando un aire de familiaridad para quienes provenían de un catolicismo que, en muchos casos, discutían seriamente. Más aún, la autodefinición como continuidad contemporánea de las enseñanzas de Jesús de Nazareth, de la Idea Nueva tergiversada por la Iglesia desde el Concilio de Nicea (325) - según se pensaba -, instalaba una pertenencia ontológica con el pasado cristiano con el cual existía una innegable relación. En suma, un fuerte imaginario católico entre los adeptos igualmente operó a favor de la incorporación de personas que no renegarían de la figura central de Jesús como único maestro espiritual. Personas que, por otro lado, los unía no solamente un parentesco más o menos directo con el catolicismo, sino que se veían atraídas por una organización que fomentaba el librepensamiento y el conocimiento científico. Sobre estas temáticas, precisamente, nos detendremos en el próximo ítem.

\section{CIENCIA, RELIGIÓN Y FE COMPROBADA}

La Escuela Científica Basilio se definió desde sus orígenes, al igual que el kardecismo, como ciencia espiritualy culto espiritista. El adjetivo de "científica" apuntaba, de hecho, tanto a su condición de centro de enseñanza de conocimientos sobre el espíritu como a su producción y adquisición. Ella no

\footnotetext{
${ }^{3}$ Mientras Blanca y Eugenio remiten a los fundadores de la institución, Pedro Basilio Portal (de quien lleva el nombre la institución) fue padre del último y se lo considera co-fundador junto a los otros.
} 
pretendía establecer un dogma. Era científica porque proponía una modalidad experimental apoyada en el uso de las mediumnidades para generar un saber sobre el mundo espiritual. De este modo, sustentó su doctrina sobre una concepción basada en la apertura crítica y el progreso del conocimiento. Esto ponía en discusión a las religiones convencionales, dado que eran entendidas como sistemas de creencia basados en "verdades aceptadas" - i.e., no cuestionadas - de fe. Las vinculaciones teológico-doctrinales y simbólicas con el kardecismo y el catolicismo definieron sus relaciones con la ciencia y la religión. De los preceptos establecidos por el espiritismo acerca de la existencia de vida después de la muerte, mediumnidades que posibilitan los contactos entre distintos mundos de existencia, reencarnación para la purificación de errores anteriores, y evolución espiritual, la idea de ciencia es central en su concepción identitaria, pragmática y ontológica. Las propuestas de Kardec para hacer del espiritismo una ciencia experimental son adoptadas y llevadas a la vida cotidiana y a las diversas actividades. La exteriorización de lo científicose manifestó no sólo como componente identitario de la práctica habitual, sino como punto de choque contra la religión. Aun cuando algunas veces puedan referirse a las religiones en general, el referente local es siempre la Iglesia Católica. La Escuela Científica Basilio proponía - y aún propone - lo que denomina como fe comprobada.

Esta magnifica ciencia no tiene secretos para nadie; habla un lenguaje claro, sin ambigüedades; en ella no hay nada místico, nada alegórico, susceptible de falsas interpretaciones. Quiere ser comprendida por todos, y lejos de oponerse a la difusión de la luz, la quiere para todos; no exige una creencia a ciegas; nos dice que antes de creer hay que ver; apoyándose sobre la razón, será siempre más fuerte que los que se apoyan en la nada (ESCUELA CIENTÍFICA BASILIO, 1948, p. 1-2).

Los interlocutores de esta cita eran tanto las creencias esotéricas asociadas al ocultismo, expresiones heterodoxas entonces contemporáneas, como las religiones sostenidas en dogmas aceptados en la fe, siendo aquí el catolicismo el principal referente. El extracto muestra una autodefinición que descansa en una diferenciación de dichas perspectivas, presentándose como un espacio absolutamente inclusivo. Aquella ecuación híbrida entre ciencia y religión, la fe comprobada, se definía como la 
certidumbre de haber entrado en el camino que conduce a la verdad. Esta no se la adquiere sin haber pasado los tormentos de la duda... La fe es también la convicción de saber, de conocer... La fe me la da el conocimiento... Cuando la fe prescinde de la razón con un cuerpo de doctrina es lo que llamamos fe ciega... Si acepto la doctrina sin comprobar, su verdad es una fe ciega. Así el hombre se vuelve fanático, opresor... Cuando el hombre no razona no puede tener fe... Ver, comprobar y después creer... Debo percibir, comprobar, y después voy a tener fe [entrevista realizada en 2002].

La fe comprobada introduce un racionalismo que pretende oponerse a un dogmatismo irracional. Dentro del universo discursivo de los actores se presentan elementos polarizados y adjetivados: la $f e$, como sustitutivo de la religión, versus la verdad, proveniente de la certidumbre de la comprobación, en reemplazo del conocimiento científico-experimental. La primera es asociada con dogmas y cuerpos doctrinales (religiosos) que son seguidos y adoptados ciegamente ("fe ciega") por hombres (y sistemas) que terminan transformándose en fanáticos y opresores; la segunda es ligada con la certidumbre de la verdad, la convicción de saber, la razón y comprobación personal. En suma, la fe comprobada proporcionaba un importante rol a la agencia individual en el sentido que correspondía al sujeto, en definitiva, ser el propio movilizador de la creencia, alejando del horizonte de la experiencia religiosa cualquier sumisión a principios no tamizados por el razonamiento individual. En este sentido, para comprender la visión crítica sobre la religión y su identificación particular con la Iglesia Católica es necesario explorar la relación histórica que caracterizó al espiritismo con el catolicismo.

Al comenzar la década de 1940, cuando la Escuela Científica Basilio comenzó a crecer sostenidamente, la política de la Iglesia frente al espiritismo cambió para tornarse más severa y vigilante. Para ese año se contaba con unos 300 socios titulares, tres años más tarde el número había ascendido a unos 1.600, al finalizar la década, en 1950, ya se sumaban 21.000 adeptos. En 1952 se registraban más de 30.000 con 50 filiales inauguradas (ESCUELA CIENTÍFICA BASILIO, 1997). Unos años más tarde, al promediar la década de 1960, la tasa de ingreso anual oscilaba alrededor de las 15.000 personas. En respuesta a este molesto crecimiento para la Iglesia, el diario católico El Pueblo 
se refería a las prácticas espiritistas como "paparruchadas que tienen tanto de estupidez” (BIANCHI, 2004, p. 221). Para 1950, la revista católica Criterio sentenciaba que,

Los componentes de la nombrada secta espiritista, a todas luces de dudosa solvencia, aparecen, sin embargo, financiando una propaganda tan profusa como costosa: distribución de plaquetas de aluminio [...] como distintivos espiritistas, en subterráneos y demás lugares de gran afluencia de público; gigantescos letreros iluminados con la leyenda 'Jesús no es Dios' colocados en sitios estratégicos de la ciudad; material empapelamiento [sic.] de muros con afiches, preferentemente en torno a determinados templos católicos; reparto de folletos descristianizantes a la salida de escuelas del Estado donde por ley se imparte enseñanza religiosa (BIANCHI, 2004, p. 222).

En cierta forma, la Escuela Basilio heredó tanto la estigmatización de la que había sido objeto anteriormente el espiritismo kardecista, como las diatribas que - desde 1882 y en adelante (BIANCHI, 2004, p. 146) - habían comenzado a disparar desde sectores católicos. El espiritismo kardecista en la Argentina sostuvo históricamente una postura anticlerical. Bianchi señala que los católicos representaban el "oponente principal frente a los cuales no era viable ningún tipo de diálogo” (1992, p. 113). La institución afirmó, por su lado, una posición militante contraria a lo que definía como "dogmatismo eclesiástico." Esta oposición tuvo lugar difusamente sobre aspectos disímiles pero se concentró, en particular, sobre dos dimensiones: 1) el hermetismo doctrinal de la religión católica; y, 2) la divinidad de Cristo. Gran parte de su historia fue, entonces, una lucha por preservar un capital simbólico de legitimidad. Bajo esta mirada de confrontación por un locus legítimo, la caracterización de "establecidos" (insiders) y "marginados" (outsiders) que, siguiendo a Norbert Elias, proponen César Ceriani Cernadas y Analía Kerman (2004) para mostrar la dinámica de acomodación social de grupos no católicos en el campo religioso argentino es más que apropiada, al tiempo que ilustra el horizonte de hegemonías y contrahegemonías religiosas en la Argentina (LUDUEÑA, 2005).

De esta manera, cuando empezó a lograr cierta notoriedad ya había antecedentes en el imaginario colectivo acerca de qué era el espiritismo. Más significativo 
aún, existían precedentes que pautarían las relaciones que una naciente institución espiritista habría de sostener con la Iglesia. Los conflictos antes citados, que tuvieron un carácter público en su momento, se explican por el proceso en el que catolicismo y espiritismo confluyeron en la misma arena sociocultural, por primera vez, a fines del siglo XIX. La tensión con el clero alcanzó su clímax para 1950, a causa de las acusaciones que desde ciertos sectores del catolicismo denunciaron la condescendencia y contactos que el gobierno de Juan Domingo Perón (1895-1974) mantenía con el espiritismo (BIANCHI, 2004; CAIMARI, 1995). Pese a estos aguzados roces, las similitudes no sólo simbólicas sino organizacionales fueron parte del mismo período. Sobre estas últimas tratará el siguiente apartado.

\section{ORGANIZACIÓN Y MATERIAL DOCTRINAL}

\section{UNA ESTRUCTURA ECLESIAL}

En su aspecto organizativo, la Escuela Científica Basilio refleja más la estructura de una entidad eclesial unificada que la modalidad descentralizada y autárquica que caracterizó históricamente al espiritismo kardecista. Posee en la actualidad más de 340 filiales distribuidas en Sudamérica, Europa, Estados Unidos y Australia. La mayoría de las cuales se crearon entre las décadas de 1940 y 1960. La autoridad de todo el organismo se concentra en un Director General Espiritual mundial. Luego, sigue un cuadro de directores organizados por país, región geográfica y función. La misma estructura piramidal se repite para cada una de las filiales. Un director a cargo de filial y otros a cargo de la coordinación de las actividades religiosas. De esta manera, se verá, la jerarquización de la autoridad y su polarización en la figura del Director General Espiritual reflejaron la unificación y homogeneización en otras esferas. Estos elementos contrastaban, nuevamente, con los parámetros del espiritismo kardecista.

Sin embargo, este ordenamiento no siempre fue igual sino que comenzó a tomar forma hacia los primeros años de la década de 1940. En efecto, con un 
crecimiento exponencial en un corto tiempo, su nuevo y carismático líder, Hilario “Lalo” Fernández (1905-1939) - Director General entre 1939 y 1974 -, diseñó una estructura que pudiera hacer frente a las consecuencias de este cambio acelerado. Entonces, el modelo eclesial, es decir, la organización regionalizada y de jerarquías parangonables con las del clero diocesano, resultó óptimo para el control zonificado de regiones que pasaban ahora a sumar adeptos que ya no sólo reafirmaban su lugar en Buenos Aires sino que, además, iniciaban una prolongación sostenida sobre áreas alejadas de la geografía nacional y, en algunos casos, internacional. Esta ampliación de los horizontes requirió de una solución inmediata. El paradigma propuesto permitía la supervisión y comunicación con otras filiales sin perder el rol de notoriedad que, en un plano estructural, ocupaba el Director General. Con todo, debe enfatizarse que aquella centralidad no descansó tanto - ni exclusivamente - en una formalidad organizacional como, primordialmente, en un atrayente e influyente carisma religioso que era característico de Fernández. Su propia figura ocupaba, estructuralmente, el mismo lugar de centralidad que le cupo a la figura de Jesús en el orden cosmovisional aunque, por supuesto, sin ser homologables una con otra. Este valor carismático de su figura es detectable en la reconstrucción histórica que suelen realizar los actores cuando se los interroga acerca de sus recuerdos sobre sucesos de la Escuela. Son comunes referencias repetidas como en la época de Lalo... o en la época de Mario...4

En este sentido, es destacable que en todos los directores hubo, si bien no un personalismo, sí una relevancia simbólica omnipresente. Cada uno de ellos trazó una línea simbólica directa con los fundadores, en tanto que fueron ellos los encargados y responsables de la conducción de todo el movimiento. En el espiritismo kardecista, por el contrario, estos "intentos de nucleamiento fracasaban sucesivamente” (BIANCHI, 1992, p. 118). Al menos, en esta forma lo había sido hasta la creación de la Confederación Espiritista Argentina en 1900, situación que tampoco revirtió el alto grado de autarquía que cada centro espírita ostentaba. Así, la unicidad de la autoridad se reflejaba en la

${ }^{4}$ Esta última referencia señala a Mario Salierno, secretario personal de Hilario Fernández, y posterior Director General Espiritual a su deceso. Ocupó esa dirección entre 1974 y 1987. 
unificación de una doctrina, la estandarización de actividades rituales, la coherencia de procedimientos formales, y la uniformización del cuerpo de profesionales religiosos mediante cursos de auxiliares, cursos para directores, charlas con el Director General, circulares y memorandos oficiales, etc., que contribuían a consolidar tales procesos. Las filiales comenzaban un recorrido que conducía inexora-blemente a la imitación del modelo representado por la sede central porteña, una suerte de romanización espiritista. Esta etapa marcó, justamente, el paso de una communitasespontánea a una normativa. En palabras de Turner, "bajo la influencia del tiempo, la necesidad de movilizar y organizar los recursos y el imperativo de ejercer un control social entre los miembros del grupo para asegurar la consecución de los fines propuestos, la communitas existencial se transforma en un sistema social duradero" (1988, p. 138). Lenta pero sin dilaciones, tanto el crecimiento como el avance hacia una cada vez más afinada burocracia weberiana derivaron en aquella forma sociológica cuya consecuencia más directa fue, entre otras, la abstracción de las relaciones sociales primarias cara-a-cara que caracterizaron a la primera etapa. Ello tampoco era extraño a lo que acontecía en los mismos barrios donde se localizaban las filiales espiritistas.

Para quienes participaban en los diferentes espacios que aparecían, la figura de Lalo reforzaba la importancia de comprometerse con la institución. De este modo, sea mediante la acción personal en distintos agrupamientos internos, la lectura del material literario - no sólo específico sino también accesible al público -, experiencias rituales, posibilidad de ser parte de un plantel con responsabilidades específicas - e.g., director o auxiliar -, etc., el activismo fue sin duda un lugar común, diferenciándose de otras denominaciones religiosas con ordenamientos que implicaban mayores controles sobre la promoción y participación interna y sobre el acceso al conocimiento de lo numinoso. Se trazó un delicado equilibrio dirigido a tomar distancia tanto del ocultismo como del dogmatismo, al que identificaba con la aceptación acrítica de verdades irrevocables. En el tránsito de este sinuoso trayecto fue centro de convergencia de sectores que, por un lado, no tuvieron que iniciarse para obtener conocimientos esotéricos - como ocurría con representantes locales ocultistas -; tampoco necesitaban, por otro lado, de mediaciones altamente jerarquizadas para el contacto con lo numinoso - como sucedía con un clero fuertemente romanizado y dotado de una estructura cada 
vez más vertical y disciplinada. Precisamente, fue a través de esta progresiva participación social, en la producción intelectual y discusión de los conocimientos, prácticas religiosas, roles y agrupaciones internas - en otras palabras, en una singular performance social -, que hizo de la Escuela Científica Basilio un órgano de puertas abiertas para sujetos que bien podría concebírselos como, empleando la acertada metáfora de Romero (1998) para los católicos porteños de la entreguerra, espiritistas en movimiento.

En este orden, esta tendencia de activismo espiritista se desplegó de forma predominante bajo contenciones marcadamente preestablecidas. La Confederación Espiritista Argentina en 1900 y, más tarde, la Escuela Científica Basilio proporcionaron las estructuras para esas prácticas provenientes de Europa, en principio, de inmigrantes españoles (MARIÑO, 1963). El extendido "juego de la copa" entre las clases medias argentinas parece haber sido, con mucho, la expresión no institucionalizada más cercana a lo que practicaban los centros espiritistas ligados al kardecismo. Mientras este último se desarrolló siguiendo una lógica descentralizada y horizontal logrando más tardía y trabajosamente una federación de sociedades espíritas, la Escuela Científica Basilio adoptó - según vimos - un modelo eclesial centralizado y jerarquizado en torno a una sede central con filiales que a su vez se subsumían en múltiples regiones y sub-regiones geográficas. La cuestión es que esta tendencia de espiritismo masivo tuvo lugar bajo el manto formalizado de una organización especial. Más aún, de un conjunto de normas y reglamentos, una denominación legal, etc., que contuvieron una liberalización no regulada de esta expresión. La sumatoria de estos elementos se conjugaría en la figura jurídica de una asociación civil, Asociación Espiritista Escuela Científica Basilio. Pese a esta estructuración de roles y funciones, la imaginación de una doctrina propia se hizo imperiosa.

\section{EL DESARROLLO DE LA DOCTRINA ESPIRITUAL}

Aunque piramidal y jerarquizada, la estructura organizacional permitió incorporar en distintas posiciones a los concurrentes de la Escuela Científica Basilio, desde directores hasta auxiliares o simples colaboradores voluntarios. Es decir, se abrió un ámbito de compromiso y acción legitimada por el propio lugar 
que cada uno ocupaba dentro de la estructura. Más allá de la adscripción oficial a cualquier cargo, los espacios informales fueron tal vez más importantes que los primeros. Caracterizada por un alto grado de participación y sociabilidad colectiva, los simpatizantes no dudaban en cumplir tareas destinadas al mejoramiento de servicios, reparaciones edilicias, atención al público, o cualquier otra ayuda necesaria para el óptimo desarrollo de la misión. En esta forma, visitas durante la década de 1950 a leprosarios y enfermos en hospitales, asilos de ancianos, realización de espectáculos varios para niños con la inclusión de artistas, edificación de pequeñas filiales por parte de futuros asistentes, ateneos juveniles y asambleas de lajuventud etc., daban muestras de un espíitu de caridad, cooperación y solidaridad, así como de dedicación para con una singular realidad social. En esta dirección se encaminaron, por ejemplo, los Dadores Voluntariosde Sangre y la Cruzada Pro-Mejoramiento Humanitario, con el resultado final de la implementación de la Obra Socialen 1954.

La Escuela Científica Basilio logró reunir de manera exitosa a un buen número de personas provenientes de los sectores populares porteños, en ese momento, más alfabetizados y con mejor llegada al sistema formal de educación. Situación que, en buena medida, se debía no sólo a la extensión de la escuela pública, sino a la influencia de una naciente empresa cultural ligada al mercado editorial y a la multiplicación de bibliotecas barriales (GUTIÉRREZ y ROME$\mathrm{RO}, 2007)$. Factores, ambos, que facilitarían notablemente el contacto y la apropiación intelectual y reflexiva del material textual que traía consigo este nuevo espiritismo. Principalmente vinculados a trabajos asalariados fabriles y domésticos, como a pequeños propietarios de comercios - en su mayoría de origen español e italiano -, "los Basilio" - como se los solía identificar públicamente -, supieron dar una explicación alternativa a cambios socioeconómicos y políticos acentuados que se desplegaban en una Argentina que, al promediar el siglo XX, vivía el nacimiento del peronismo. ${ }^{5}$ Este último, además de tratarse de un movimiento social y político que dividiría al país en amigos y enemigos,

\footnotetext{
${ }^{5}$ Fundado por Juan Domingo Perón en 1945, el peronismo fue el movimiento político de masas más importante de la República Argentina. Sus bases doctrinarias rescataban fundamentalmente el rol de la justicia social en la sociedad a través de la protección estatal de los derechos de los trabajadores asalariados.
} 
se dirigía a disparar el ascenso de las masas a la política y al logro de más justos estándares de vida - de allí que aquél adoptara el nombre de Partido Justicialista. Por este motivo, no es imprudente colocar al espiritismo Basilio como el primer emergente de religiosidad popular urbana no católica de carácter masivo que se originó en Buenos Aires en la primera mitad de la centuria pasada. La presencia multitudinaria de sus adeptos en diferentes actos, rituales diarios, eventos públicos, declaraciones periodísticas y conquista de la esfera pública hicieron de él un grupo heterogéneo y popular, con altos estándares de participación y sociabilidad y, por ello, fue conocido en el espacio social más amplio, principalmente, aunque no sólo, porteño.

Esa apariencia cristalizada en lo institucional tuvo un claro correlato en el acceso a saberes espirituales. Se presentó a sí misma como promotora de un conocimiento sencillo y comprensible por todos aunque, ciertamente, intentó hacerlo con solidez filosófica y elocuencia explicativa. En este orden, nunca apareció como una "sociedad iniciática" al estilo Rosacruz (CERIANI CERNADAS, 2003). El kardecismo, por otra parte, tampoco se inclinó a hacer del espiritismo un saber secreto restringido a una elite ilustrada; más bien, concentró su interés en fortalecer y difundir el estudio de los trabajos clásicos de Allan Kardec. Según afirmó Bianchi, “[e]l iniciado, al sentirse partícipe de esa elite, podía entonces hacer desva-necer la dura realidad [...] tras la apariencia de esa ficticia superioridad. De allí que el ocultismo pueda prender sobre todo en las capas medias urbanas" (2004, p. 232).

En términos doctrinarios, se impulsó la popularización de los conocimientos sobre el más allá, lo cual se produjo gracias a una distribución y acceso al material de estudio que se divulgaba a partir de sendas publicaciones. Entre ellas, estaba la Revista Hermanos, que inició su circulación en 1943 para traer las principales novedades de un grupo que comenzaría por ese tiempo a crecer sostenidamente. Luego, en 1953 salía el primer número de Espiritismo, en donde un artículo de título "Jesús no es Dios" prestaría el eslogan para el multitudinario evento celebrado en el estadio Luna Parkal año siguiente. Sin embargo, fueron sin duda las llamadas conferenciaslas más populares. Reconocidas muchas veces por su color, como la serie rosa y más tarde la verde, se caracterizaron por ofrecer un compendio de conocimientos sencillos aunque de valorable densidad 
para sus lectores. Editados bajo la modalidad de pequeños breviarios, las conferencias estaban organizadas en temas que, en conjunto, componían una colección heteróclita. La juventud, los vicios, la libertad, el amor, el egoísmo, etc., eran parte de algunos de los múltiples temas que, desde una visión espiritual, ocupaban los pequeños volúmenes. Una de las más famosas, la serie de Psicología Mediumnímica del Ser, se vendía a un módico precio y solía estar en todos los hogares. Acompañaban frecuentemente la lectura personal, el estudio sobre el mundo espiritual y sus aportes para la comprensión de situaciones de la vida cotidiana. Las conferencias contribuían a la construcción de un modelo explicativo de la realidad. Ellas también solían ser leídas públicamente en charlas para asistentes externos, interesados o visitantes que tenían intenciones sea de conocer con mayor profundidad la propuesta Basilio o, directamente, de ingresar como socios. En estos casos, tal fue la relación entre aquellos encuentros y estas singulares publicaciones que las reuniones pasaron a llamarse conferencias para visitantes, dado que en esos mismos espacios se leían abiertamente las series homónimas. Siempre acompañadas por los comentarios explicativos de algún director o directora encargada de la charla. Hacia mediados de siglo, los domingos, unos de los días estipulados para estas convenciones, se aglutinaban apretadas concurrencias para escuchar las conferencias a las que asistían tanto hombres como mujeres.

Una de las consecuencias directas de esta entrada masiva a la literatura espiritual fue, indudablemente, la imposibilidad de establecer un núcleo intelectual esotérico con un monopolio restringido del saber (véase, por ejemplo, Boas, 1993). Como resultado, la divulgación fue compatible con una democratización del conocimiento que se reveló en conversaciones, debates y cruce de opiniones que, en ocasiones, tenían lugar en encuentros informales entre los adeptos u otros con los que se hablaba acerca del espíritu. Estos ámbitos coloquiales, que no pocas veces tenían lugar en charlas de café en las que aparecían estos temas, eran parte de la extensión informal de las actividades rituales y colaborativas que se desarrollaban en relación directa con la vida institucional. En ellas se reforzaban los lazos de sociabilidad existentes o se creaban otros nuevos, siendo los intercambios sobre doctrina el leitmotiv de muchos de esos eventos. Aun cuando el compromiso con el estudio e indagación teológica fue heterogéneo, allí se compartían conocimientos, se cruzaban interpretaciones sobre la marcha del 
mundo a la luz de estos saberes espirituales, se adentraba en diálogos metafísicos, o bien se discutía literatura específica para ampliar o complementar nociones ya existentes. Asimismo, el cruce de opiniones sobre la realidad del organismo, en particular el de la propia filial - aunque podía surgir algún que otro comentario acerca de otras -, constituía parte casi ineludible de estos diálogos. En suma, a través de estos mecanismos participativos se eludía, al menos en principio, una jerarquización del saber accesible sólo a una elite a través de una apropiación esotérica como ocurría en otras expresiones del campo religioso (CERIANI CERNADAS, 2003). De manera que la estructura organizativa no determinaba la llegada al corpuscognitivo.

La Escuela Científica Basilio se presentaba como un espacio capilar susceptible de asimilar saberes externos que, en ocasiones, podían entenderse bajo la propia cosmovisión y que, aunque traducidos en otros códigos, reafirmaban la sensación de certeza conferido por la propia perspectiva del mundo. De este modo, pese a los esfuerzos que desde la dirección se realizaban por definir y circunscribir los límites - como la inscripción legal en el Registro de Cultos, por ejemplo -, se mantuvo como una organización de fronteras permeables a adherentes esporádicos que buscaban conocimientos para su propio acopio, quienes, además, venían impulsados por un imaginario en el cual la Escuela Científica Basilio gozaba de un serio prestigio. Ello sucedió particularmente durante la emergencia y desarrollo de la New Age, en la que algunos simpatizantes frecuentaban las conferencias para principiantes e, incluso, llegaban a prestar juramento como nuevos miembros. Sin embargo, existieron otros mecanismos a través de los cuales la acción, participación, sociabilidad y compromiso se vieron revitalizados; ellos estuvieron dados por las representaciones que construían, junto con otros dispositivos simbólicos, una identidad espiritista.

\section{CENTROS ESPIRITISTAS Y SOCIABILIDADES BARRIALES}

Aun cuando la organización cuenta con una jerarquía zonal que responde a la distribución espacial de aquellas sedes, durante la mayor parte de su historia las filiales contaron con un sólido anclaje barrial que acompañó el crecimiento urbano de la ciudad de Buenos Aires. Siendo los barrios porteños recintos de 
sociabilidad entre sus heterogéneos habitantes, las filiales - como clubes, asociaciones, sociedades de fomento, comités, etc. - respondieron a estas lógicas barriales de construcción de redes sociales de cobertura local y, muchas veces, circunscripta a los límites de barrios que durante buena parte de la primera mitad del siglo XX pujaban por lograr una más intensa comunicación.

En este sentido, era común identificar el número de filial con el barrio en donde aquella se ubicaba. Así, la filial 3 era la de Flores, la 68 la de Barrio Norte, etc. La sede central, más aún, se identificaba por su domicilio en el barrio de Almagro, Rawson 53. Lo mismo valía para las recientes fundaciones de localidades del cordón suburbano del Gran Buenos Aires en un crecimiento que, aunque desparejo, acompañaban el compás que marcaba la Capital Federal. Filiales recientes como las de San Justo, Munro, Lanús, San Martín, etc., eran susceptibles a idénticos procesos. De este modo, cada sede por lo general solía reunir sus simpatizantes de zonas aledañas. Entre aquellos era usual que en algunos casos los nuevos seguidores provinieran de amistades, o incluso llegaran a ser familiares directos, de miembros estables que terminaban prolongado las redes sociales externas al interior de la Escuela. De esta forma había llegado una adepta, a quien en 1946 "un hermano de la Escuela le indicó lo que podía encontrar en ella y fue así como se asoció junto con su esposo, llegando más tarde sus padres y hermano" (ESCUELA CIENTÍFICA BASILIO, 1968, p. 5). Ello proporcionaba un cálido ambiente familiar en los asiduos asistentes entre los que, precisamente, se hallaban numerosas familias donde hombres y mujeres, y más tarde hijos e hijas, formarían parte de los concurrentes al salón de prácticas espirituales. En este campo de inclusión, las fiestas de los niñosacostumbraban a dar un lugar especial a estos últimos, muchos de los cuales serían en el futuro nuevos adherentes instruidos desde temprana edad en los rudimentos de la ciencia espiritista. En estas dinámicas sociales se ponían de manifiesto altos grados de compromiso. Ejemplos de ello lo fueron la contribución de numerosos hermanosen la construcción misma de algunas filiales, tal como sucedió con la filial 3 de Flores o la 79 de Lomas del Mirador, entre otras.

En adición a estas sociabilidades barriales existían otros aspectos ligados a los denominados guías espirituales. Cada una de estas escuelas satélites de la central poseía su propio guía. En este universo cosmológico, mientras que las figuras religiosas de Dios, Jesús, María y José cimentaban el sistema simbólico 
al imaginario cristiano, el conjunto de los guías de las filiales se relacionaba con un ideario heterodoxo - mayoritariamente - no religioso. En estos casos, solían presentarse figuras prominentes que respondían al ideario nacional. Por ejemplo, el General José de San Martín, Manuel Belgrano y Domingo Faustino Sarmiento, entre otros héroes míticos de la historiografía argentina. Igualmente aparecían personalidades relevantes de las letras y las artes como Alfonsina Storni, Carlos Gardel, José Martí, Víctor Hugo o Agustín Magaldi. En tanto, otros personajes se correspondían con un imaginario mucho más internacionalista y culturalmente occidental, respondiendo al proclamado ecumenismo del mensaje espiritista. Entre estos últimos estaban René Descartes, Sócrates, Sigmund Freud, Aristóteles, Luís Pasteur y Abraham Lincoln, entre muchos otros. Todos ellos mostraban la senda correcta y la misión cumplida durante la encarnación material. A través de sus respectivas cualidades, la producción literaria, innovación científica, pericia militar, sensibilidad social, solidaridad política, amor al próximo, etc., verificaban en existencias concretas el camino de progreso personal como la evolución espiritual transformándose, por lo tanto, en ejemplos de vida a ser emulados. En todos ellos, no obstante, persistía una idéntica cualidad que era la virtuosidad, el cumplimiento del debery de la misión, características fundamentales del ethosespiritista (LUDUEÑA, en prensa).

Del mismo modo en que los barrios porteños podían aparecer como deícticos identitarios para ciertas filiales, algo similar ocurría con los guías. Solía reconocerse o referirse a la sede por su guía, la filial de Carlos Gardel... o la de San Martín... En este juego de denominaciones e identificaciones, barrio, guía y filial se manifestaban como los referentes simbólicos de un espacio de sociabilidad religiosa que, aunque más no fuera a través de la acción colectiva de pequeños núcleos humanos, reforzaba, recreaba y motorizaba nuevas redes sociales. Mayormente de naturaleza barrial, estas últimas acentuaban la relación de los adeptos con el barrio y, en consecuencia, desplegaban procesos de construcción de la localidad (APPADURAI, 2001). Uno de los indicadores de estos procesos fue otra categoría de guías espirituales distintos de las reconocidas figuras nacionales e internacionales. Esta vez, dada por la designación de personalidades comunesque, dicho sea de paso, gozaban de un nexo existencial específico con el barrio y la filial a la que habían sido asignados por nombramiento del Bien (ver nota 1). Sobre un total de 344 filiales, 110 guías (32\%) pueden suscribirse al primer grupo, mientras 
92 hacen lo suyo con relación al segundo de ellos (27\%). El tercer agrupamiento, el de los guías que en vida fueron miembros activos de alguna filial, suman 137, representando a la categoría más numerosa (40\%). Finalmente, la clase minoritaria es la de guías considerados como espíritus de luzy que, por definición, nunca encarnaron.

Existían otros elementos que, junto al barrio, las sociabilidades locales y los guías, contribuían a la popularización de esta tendencia del espiritismo porteño. Se trataba de las características generales de los que componían ese conjunto más numeroso, es decir, las personalidades comunes. Por ejemplo, las biografías reflejaban las vidas ejemplares de sujetos que, desde el más allá, seguían comprometidos con la misión. De esta manera describía una publicación de 1968, titulada Nuestros Guías Espirituales, la vida de uno de aquellos sujetos.

[L]as circunstancias de la vida hicieron que a los 13 años emigrara a la Argentina, y viviera en una casa cercana al mercado de Abasto, en Buenos Aires [...] pudo llegar a colocar un negocio de ventas al por mayor, de frutas y verduras, en el mercado de Abasto; en él, por su honestidad era considerado un hombre de gran bondad y de excelentes virtudes [...] La orientación brindada a su hogar tuvo las nociones de virtud de todo buen padre [...] llegó a su conocimiento la existencia de la Escuela Científica Basilio [...] Comenzó a asimilar la Enseñanza Espiritual con una profundidad tal, que rápidamente se convirtió en un gran difusor del espiritismo (ESCUELA CIENTÍFICA BASILIO, 1968, p. 6-7).

Este fragmento de la biografía de Pascual Cuartieri, guía de la filial 42 de San Justo, una localidad del cordón periférico de Buenos Aires, exaltaba los orígenes inmigrantes y humildes como su compromiso con una enseñanza y un ethos singular. De indudable ligazón con sectores populares urbanos o suburbanos, los adherentes - entre los que se contaba una importantísima asistencia femenina - hacían de la filial un segundo hogar, llevando su activismo y participación del barrio a la Escuela. Sin embargo, no eran estos los únicos lugares en donde aquellos se revelaban. Los espacios rituales se mostrarían, en este sentido, más que propicios para la acción individual y colectiva. 
PERFORMANCE Y POPULARIZACIÓNDE UNA...

\section{LAS PRÁCTICAS ESPIRITUALES}

\section{LA MEDIUMNIDAD COMO PRÁCTICA SOCIAL}

La mediumnidad es, sin duda, la quintaesencia doctrinal de la enseñanza. En particular, resulta ser de una importancia primordial para el ejercicio del espiritismo científico que la Escuela Basilio proclamó practicar desde sus más prístinos comienzos. El origen mítico ya había estado marcado por la práctica mediumnímica a partir del rol central de los fundadores. Alejada por completo de una condición de don exclusivo de unos pocos, aquella logró colectivizarse para pasar a ser patrimonio constituyente de la naturaleza humana. Esta concepción, contraria a cualquier elitismo, fortaleció las agencias individuales y las disparó en dirección a la gestión de la propia acción personal, por ejemplo, en la arena de las moralidades y de sus vínculos con la mediumnidad (LUDUEÑA, en prensa). En esta corriente del espiritismo no se formaban elites de médiums tal como podía ocurrir en la vertiente kardecista.

En este último caso, recordemos, fueron los de apellido francés los que gozaron de mayor prestigio (BIANCHI, 1992). Asimismo, existió - y continúa operando hoy en día - una significativa economía de producción y circulación de los capitales simbólicos de los médiums, aun cuando se reconociera en esta cualidad una de carácter general y potencialmente presente en todos los sujetos. Ello fue particularmente enfatizado en los médiums normalmente elegidos para materializar - i.e., incorporar un espíritu en el cuerpo del médium - a Jesús de Nazareth, situación que sólo se producía en eventos de suma relevancia. En estos casos, la materialización del llamado Maestroconstituye una de las más altas satisfacciones y honores para un médium. En suma, puede decirse que la proclamación de la condición mediumnímica de todos los seres humanos como capital de posesión común adquirió un matiz militante y declamativo. La certeza de la tenencia de tal cualidad instó a mejorar y perfeccionarse a través de la adquisición de una competencia operativa y de la instrucción sistemática en materias tanto espirituales como materiales. 
De la misma manera en que se destacaron políticas de orden exotérico más que esotérico (BOAS, 1993), lo que tuvo una relación directa con la popularización de los saberes espiritistas, igualmente se trasladó al entorno ritual traduciéndose en una alta participación. Participación que, por otra parte, siempre implicaba el uso de la mediumnidad. En otras palabras, todos podían asistir y formar parte activa de puestas en escena en las cuales - por lo general - los actores contaban con roles establecidos. Esta participación, aunque más no hubiera sido como auditorio, no era sinónimo de pasividad. Además de la posibilidad de presenciar de primera mano un ritual que se definía por su carácter público, y de abarcar conocimientos que cualquiera de los presentes - incluso de los legos - podían fácilmente adquirir, la performatividad hacía de la instancia ritual una verdaderamente singular. Ello tanto por el ritmo mismo del ritual, como por los efectos que tenía sobre las propias sensibilidades de los sujetos.

Debe recordarse que la misma acción de sociabilidad, muchas veces concretada en asociaciones de tipos y finalidades heterogéneas, tal como hemos visto, tenía necesariamente un correlato ritual. Resulta imposible entender una dimensión sin referir a la otra. Posteriormente, de hecho, el debilitamiento de la primera trajo acarreado el decaimiento de la segunda. Dicho de otro modo, la misma sensación de pertenencia, colaboración y participación que podía experimentar, por caso, un miembro de los Dadores Voluntarios de Sangre, guardaba correlación con lo que sucedía en el salón de actos espirituales. Esta idea durkheimiana del ritual (DURKHEIM, 1993), como hacedora de consenso y moralidad colectiva, es claramente aplicable a la situación de la Escuela Científica Basilio de ese momento. Puede argumentarse que fue precisamente el acceso público al ejercicio de una performance mediumnímica, uno de los elementos determinantes de la popularización de esta tendencia del espiritismo a través de una súbita masificación de las prácticas espirituales. La performance, de este modo, es tomada como mecanismo microsociológico de construcción de lo social y, en este caso en particular, también de realización y teatralización de lo popular. Al decir de Néstor García Canclini,

[Lo popular] No es un concepto científico, con una serie de rasgos distintivos susceptibles de definirse unívocamente. Por lo mismo, no se agota en una visión 
épica de la propia historia de los grupos que la sustentan, en la que "lo popular" se opusiera compacta y enérgicamente a lo que no lo es. Popular designa la posición de ciertos actores en el drama de las luchas y las transacciones. Por eso, algunos hemos sugerido pasar de una caracterización épica a otra teatral o melodramática de lo popular (2006, p. 8).

\section{Dicho de otra forma,}

lo popular se pone en escena [...] con el sentido contradictorio y ambiguo de quienes padecen la historia y a la vez luchan en ella, los que van elaborando, como en toda tragicomedia, los pasos intermedios, las astucias dramáticas, los juegos paródicos que permiten a quines no tienen posibilidad de cambiar radicalmente el curso de la obra, manejar los intersticios con parcial creatividad y beneficio propio (GARCÍA CANCLINI, 1992, p. 260).

En este caso, y muy seguramente en otros, lo popular, como proceso social y cultural, se realiza a través de esquemas rituales que permiten la escenificación de performances (BAJTÍN, 1987), posibilitando la canalización de sensibilidades, inquietudes filosófico-ideológicas y existenciales concurrentes - en algún grado - con ciertos elementos cosmológicos de la religiosidad en cuestión. Entonces, si lo popular es procesual y nunca nos es simplemente i.e., empíricamente - dado en el mundo real, y la popularización es el proceso a través del cual una cierta expresión religiosa - o de otro tipo - logra captar eso popular al menos por un corto período de tiempo, es el mismo hacer- es decir, la acción misma y, en particular, su expresión ritualizada en la performance - su materia principal y el que lo define como tal. En suma, tanto la imaginación doctrinal como la creatividad preformativa, dieron lugar a la construcción de una religiosidad desde abajo. En este contexto, el hecho de que en estos sectores cuajara el pensamiento científico, o se intentara una apropiación sistemática de su sentido y aplicación operativa, puede obedecer a que sólo mediante él podían los sectores populares construir cosmologías no sancionadas exclusivamente desde arriba y dirigidas a regular las prácticas sociales y las moralidades subalternas.

La noción de progreso y la - conceptualmente adyacente - idea de evolución espiritual, concurrían en certificar la posibilidad real de una mutación de las 
condiciones sociales existentes, aunque más no sea en una vida futura. El ascenso acelerado del peronismo, como expresión articulada de los sectores populares urbanos, atestiguaba lo mismo en una idéntica dirección, es decir, que el cambio social - y, por ende, el personal - no representaba algo imposible. Sin embargo, tales deseos no se expresaban en propuestas políticas explícitas, al menos, desde los discursos. Según lo expresaron Daniel Míguez y Pablo Semán recientemente, " $[t] a l$ vez la cultura de los sectores populares surja en algún grado de 'elecciones' y tal vez éstas tengan relevancia y funcionalidad que no son sólo resistenciales: tienen valor político porque no se acomodan al deber ser, pero no surgen de un proyecto de contestación aunque lo ejerzan" (2006, p. 15). En ocasiones, sin embargo, tanto la mediumnidad como la performatividad fueron transmisoras de politicidades subterráneas. Sobre la última tratará el próximo ítem.

\section{PERFORMANCE Y RITUAL}

Según se afirmó, la sostenida dinámica participativa, colaborativa y asociacionista no se distinguió sustancialmente - en intensidad - respecto de la intervención registrada en los contextos rituales. En este caso, se tomaba distancia de lo que sucedía en el catolicismo, otra expresión religiosa que desde comienzos de siglo había dado muestras de creciente vitalidad (DI STEFANO y ZANATTA, 2000; ROMERO, 1998). Sin embargo, en el plano de las ideas como en el de las prác-ticas, el espiritismo Basilio confrontaba y salía victorioso frente a un catolicismo que para la década de 1950 endurecía posiciones, ofrecía poco o ningún espacio para la crítica teológica, daba un lugar acotado a la participación ritual, y toda acción posible se reducía a la actuación en asociaciones laicales que, muy rápidamente para aquel tiempo, habían comenzado a pasar a la órbita de la autoridad diocesana restando posiciones directivas a los laicos (LUDUEÑA, 2007b). Esta similitud asociacionista presente en el catolicismo como en la célebre escuela espiritista, hace presumir la existencia de una lógica transversal en el campo religioso y, muy probablemente, en el espacio social más general, cuyos canales de expresión - en este caso religiosos - se hicieron - no sin dificultades - fieles ecos. 
Las mismas personas que se sumaban a cada una de esas empresas espiritistas mostraban igual grado de compromiso al momento de asistir a los actos y eventos, así como a las prácticas más cotidianas y ordinarias. Esta activa intervención ritual se canalizaba a través de cursos bien específicos; entre ellos, se incorporaron actividades como el culto a Dios, liberación espiritual, fluido espiritualy estimulación mediumnímica, junto a otros. En concordancia con estas últimas, existía una fuerte convicción y certeza acerca de la efectividad espiritual y material de cada una.

Por otra parte, las multitudinarias sesiones mediumnímicas - denominadas videncias-, en las que se congregaban cientos - y muchas veces miles de adeptos, daban lugar no sólo a la sensación persistente de ser testigos privilegiados de un evento extraordinario - en el sentido más literal de lo numinoso propuesto por Rudolf Otto (1980) -, sino, además, de ser parte fundamental de la adquisición de saberes únicos sobre el mundo espiritual y material. Actos masivos como lo fueron los reiterados y famosos encuentros del Luna Park de Buenos Aires en 1950, 1954, 1957, 1959, 1965 y 1967, con cobertura de la prensa, ilustraron el afán de popularización de un conocimiento que debía ser accesible a todos. En estos escenarios, la eficacia simbólica (LÉVI-STRAUSS, 1992) de tales situaciones de umbral abonaba en la sensibilidad de los actores la inapreciable sensación de ser parte de una verdad que muchos ignoraban, o que si contaban con ella preferían desconocerla o, al menos, negársela a una mayoría para preservar las propias cuotas de poder. En este último caso, volvían a ser los eclesiásticos y otros ocultistas los que impulsaban este encubrimiento sobre el más allá que la Escuela pretendía militantemente promover.

Desde 1932, el Luna Park había sido escenario de actos públicos ampliamente difundidos como bailes de carnaval, festivales y, más tarde, memorables combates boxísticos. En uno de aquellos festivales, se cuenta, Juan Perón conoció a Eva Duarte en 1944 con motivo de una celebración dirigida a la recaudación de fondos para las víctimas del terremoto de la provincia de San Juan de aquel mismo año. Por esta razón, el Luna Park, como espacio ritual de enunciación discursiva elegido por los Basilio, fue sin duda un ámbito de construcción y conquista de lo popular. En 1967, durante la celebración del $50^{\circ}$ aniversario se llevó a cabo una de las más recordadas videncias. A través del uso de la 
mediumnidad vidente, se exploraron conocimientos sobre la vida extraterrestre y se realizó un desdoblamiento, el cual consistía en la separación voluntaria del espíritu del cuerpo para conducirlo a un sitio predeterminado. Con un estadio repleto y la materialización en tres médiums que incorporaban los espíritus de los fundadores y del mismo Jesús de Nazareth, el Director General describía con detalle quirúrgico las características corporales de los seres de otros mundos como los lugares que la videncia le mostraba a él y a los otros videntes presentes. En tanto, la multitud observaba y escuchaba casi hipnotizada la pormenorizada narración (ESCUELA CIENTÍFICA BASILIO, 1967, 1997). La realización de estos eventos, que como el desdoblamiento remitían a una suerte de teletransportación del cuerpo - etéreo, en este caso - y a la descripción de formas de vida extraterrestre - en una sociedad occidental cada vez más acostumbrada a narraciones fantásticas sobre objetos celestes inexplicables -, anclaban los rituales en discursividades populares más extensas de la ciencia ficción, reafirmando, sin embargo, que lo ficcional no lo era tanto y que, por lo tanto, su conocimiento científico-espiritual era más que posible.

Estos despliegues rituales no eran inusuales y solían desarrollarse, con más frecuencia, en la sede central de Rawson 53; siempre con una concurrencia numerosa que, aun sin la capacidad vidente, se sumaba a un conjunto inquieto que producía colectivamente un saber específico. Pese a que en todos los casos el Director General aparecía como el único interlocutor de Jesús, la emotividad de quienes creían en su presencia en espíritu los colmaba hasta las lágrimas. Estos grandes acontecimientos en los que el amado Maestrose presentaba ante los privilegiados participantes, también se realizaban en recintos más acotados y cotidianos. En este caso, el escenario por excelencia para el desarrollo de las prácticas es, y fue desde entonces, el llamado salón de prácticas espirituales - originalmente, salón de trabajos espiritistas. Bajo esta estrategia se aseguró su control, el cual, mediante la sanción normativa sobre liturgia y usos del espacio y tiempo ritual, pautaba con cierta rigurosidad aspectos preformativos y experienciales del culto. La prohibición estricta de realizar este último en hogares individuales aseguró y exaltó el valor simbólico propio, como la supervisión permanente de las experiencias religiosas colectivas por parte de la autoridad.

En este orden, sin embargo, la sensación que por momentos invadió a no pocos afiliados acerca de la posibilidad de cierre de sus filiales permitió amasar 
la idea de que los hogares podrían convertirse en espacios rituales, es decir, en una suerte de escuelasdescentralizadas de emergencia. Estas inquietudes colectivas, por momentos insistentes, atestiguaban - a la manera de "temores morales" (GOODE y BEN-YEHUDA, 1994) - ciertas sensaciones de persecución estatal y de condición de actor subalterno en un espacio de hegemonías políticas y religiosas. Desde una perspectiva más positiva, no obstante, daban cuenta igualmente del potencial de las redes de sociabilidad existentes y su utilidad como salvataje social para situaciones extremas de persecución religiosa. Esas proyecciones corroboraban el espíritu contrahegemónico latente en un lugar donde se habían enfrentado serias amenazas eclesiásticas. Para un grupo numéricamente significativo como el de los Basilio, y en un marcado contexto de inestabilidad política, económica y social como lo fue gran parte de la Argentina del período, tales miedos no eran infundados. Más todavía, teniendo en cuenta que la Iglesia persistía como un actor social que no renunciaba a su llegada política al estado nacional, sobre todo, en las prolongadas dictaduras militares -"Revolución Libertadora" (19551959), "Revolución Argentina” iniciada por Juan Carlos Onganía y heredada por sucesivos militares (1966-1973), y el "Proceso de Reorganización Nacional" (1976-1983) -, aquel temor moral no dejó de dar muestras de vitalidad.

Pese a ello, el salón de actos continuó siendo el espacio de actividad ritual por excelencia. En él se desarrollaba cotidianamente, y a todo horario desde bien entrada la mañana, la liberación espiritual. Antes o después del trabajo en la oficina o la fábrica, adeptos y adeptas se encontraban en una esfera de intensa actividad ritual - y, por su puesto, también social, cuando las labores los llevaban a actuar fuera del salón -. Consistente en la combinación de un movimiento uniforme de manos y una actitud de elevación espiritual - que se basaba en un direccionamiento de los pensamientos hacia el Bienen un recitado casi mántrico que repetía Dios y Jesús, Dios y Jesús...-, los socios participaban activamente en el desarrollo de una performance cuyo objeto era contribuir en la tarea de reparación de los espíritus del Error (ver nota 1). En una muestra más que contundente de la vinculación entre la adscripción popular de buena parte de los afiliados y la performance ritual - en otro plano, de la relación entre política y religión -, el salón de actos de Rawson 53 vibraba exaltado, poco después del derrocamiento de Perón - el 16 de septiembre de 1955 -, desde las 6 de la 
mañana hasta altas horas de la noche y durante una seguidilla de extenuantes jornadas, por la liberación de los espíritus del Errorque impulsaban el asesinato nunca consumado - del general derrocado por militares golpistas. Esto último no sólo reafirmaba la conexión ontológica entre mundo espiritual y material sino, más importante aún, verificaba la extendida convicción en la eficacia simbólica - pero sobre todo social y política, en este caso - de la liberación, sacándola de una mera performance circunscripta a espacios y tiempos rituales. En este sentido, en definitiva, la efervescencia performativa permitió, más que cualquier otra, dar rienda suelta a la posibilidad de escenificación de lo popular. Pero, asimismo, de la popularización de las prácticas y creencias de la Escuela Científica Basilio, en tanto y en cuanto, la acción ritual podía llegar a homologarse - efectividad simbólica mediante - a la acción política efectiva - entre otras - sobre hechos que, por los infortunios de la situación presente - más todavía tomando en cuenta la larga proscripción del peronismo entre 1955 y 1972 -, excedía alcances pragmáticos posibles de los sectores populares.

\section{CONSIDERACIONES FINALES}

El abordaje de la Escuela Científica Basilio ofrece una entrada a las sensibilidades religiosas de los sectores populares urbanos de la ciudad de Buenos Aires de mediados del siglo XX. Este trabajo intentó aportar respuestas para el interrogante acerca de qué manera este espiritismo se tornó popular en un período específico de la historia argentina, y cuáles fueron los factores que más influyeron en dicho proceso. Nuestra respuesta fue que la emergencia de un espectro singular de performances rituales favoreció e incluso impulsó esa popularización. Por lo tanto, esta última se debió tanto a la multiplicación de los adherentes como a la participación ritual - y social en general - que la institución estimulaba entre sus integrantes. La Escuela Basilio demostró transformarse en un espacio social de condensación de las preferencias y sensibilidades religiosas de los sectores populares urbanos porteños - aunque no sólo de ellos - al promediar el siglo XX. En un ambiente generalizado de profunda presencia católica, en la sociedad y en el estado nacional, es lícito situar a este espiritismo como una modalidad de reacción contrahegemónica en el campo religioso, materializado a partir de 
representaciones alternativas a los discursos dominantes - aunque cada vez menos a partir de los años de 1960 - sobre lo simbólico-religioso.

En suma, puede afirmarse que cinco elementos principales determinaron la popularización de esta tendencia espiritista. Primero, la accesibilidad a un conjunto de saberes específicos y su difusión, tanto entre adeptos como entre personas ajenas a la Escuela Basilio; ello se logró mediante la publicación y reedición de las llamadas conferencias, y de las numerosas charlas públicas. Todos estos conocimientos, dicho sea de paso, proporcionaron una explicación lógica, coherente, y de fuerte y atractiva solidez argumentativa para los participantes. En segundo lugar, y de forma paralela a lo doctrinal, otro factor fue la invitación a una actividad ritual donde la performance daba amplio lugar a la invención individual. Tercero, la posibilidad de ser parte de una estructura que por jerárquica no era restrictiva, al tiempo que brindaba posibilidad de ascenso a personas interesadas en obtener grados más altos de compromiso; por ejemplo, a través del posicionamiento en cargos de dirección bajos e intermedios. Todo ello se tradujo al ritual dando posibilidades de contactar a lo numinoso con escasa intercesión eclesial - al menos en comparación con otras ofertas religiosas -. Es decir, pese a la verticalidad organizativa persistió una horizontalidad corporativa. Cuarto, el desarrollo de grupos y redes de asociaciones que actuaron tanto dentro como fuera de los marcos institucionales; todo ello en concordancia con una sociedad que hacia del asociacionismo un modus vivendi. Quinto, un fuerte anclaje barrial solidificando lazos sociales preexistentes. La estructura descentralizada permitía apropiaciones localizadas del discurso religioso que, aunque cada vez más pautado por efecto de la normativización, facilitó la participación social y ritual reforzándolas en cada filial, al tiempo que enlazaba a los espiritistas con una identidad más global y abstracta.

Finalmente, cuatro dimensiones macrosociales contribuyeron a su rápido crecimiento, asegurando la compatibilidad simbólica con las estructuras de sentimiento de los sectores populares urbanos. La primera refiere al estado extendido de asociacionismo y fomentismo en los barrios porteños del período; aspecto que se reflejó tanto en el conglomerado parroquial y en las sociabilidades católicas, como en las escuelas Basilio surgidas a partir de la década de 1940. En segundo lugar, la disponibilidad social de sectores alfabetizados y familiarizados con hábitos de lectura ampliamente difundidos por una ascendente industria 
cultural basada en el desarrollo del mercado editorial. En tercer lugar, el estado de movilización de las masas urbanas y su incorporación al mundo de la política de la mano del peronismo. En cuarto lugar, la socialización en un entorno donde figuras católicas como la de Jesús, María y José no eran del todo extrañas a la experiencia religiosa de sectores populares contemporáneos a los intentos eclesiásticos de catolización de la sociedad argentina. Dentro de este plan general de la Iglesia católica, no fue menor la vinculación con ese universo cosmológico a través de la cada vez más extendida red de parroquias católicas en Buenos Aires. En suma, la Escuela Científica Basilio supo subirse a caballo de procesos sociales de más amplio alcance y esta fue, en no poca medida, la fórmula de su popularidad.

\section{REFERENCIAS}

APPADURAI, Arjun. The Production of Locality. In: BEYER, Peter (comp.). Religion in the Process of Globalization. Würzburg: Ergon Verlag, p. 99-123, 2001.

BAJTÍN, Mijail. La Cultura Popular en la Edad Media y en el Renacimiento. El Contexto de François Rabelais. Madrid: Alianza, 1987.

BANCHI, Susana. Los espiritistas argentinos (1880-1910). Religión, ciencia y política. In:AA.VV. Ocultismo y Espiritismo en la Argentina. Buenos Aires: CEAL, p. 89-128, 1992.

. Historia de las Religiones en la Argentina. Las Minorías Religiosas. Buenos Aires: Sudamericana, 2004.

BOAS, Franz. El significado etnológico de las doctrinas esotéricas. In: RENOLD, Juan M. (comp.). Antropología Cultural. Buenos Aires: CEAL, p. 41-45, 1993.

CAIMARI, Lila. Perón y la Iglesia Católica. Religión, Estado y Sociedad en la Argentina (1943-1955). Buenos Aires: Ariel-Espasa Calpe, 1995.

CERIANI CERNADAS, César. Tradición, modernidad y agencia en el imaginario esotérico rosacruz. In: III Jornadas de Ciencias Sociales y Religión, 2003, Buenos Aires. 
CERIANI CERNADAS, César y Analía KERMAN. Establecidos y marginados en el campo esotérico argentino. In: IV Jornadas de Ciencias Sociales y Religión, 2004, Buenos Aires.

DE PRIVITELLIO, Luciano. Vecinos y Ciudadanos. Política y Sociedad en la Buenos Aires de Entreguerras. Buenos Aires: Siglo XXI, 2003.

DI RISIO, Mónica; Alejandro IRAZABAL. Escuela Científica Basilio. In: FORNI, Floreal; MALLIMACI, Fortunato; CÁRDENAS, Luis. Guía de la Diversidad Religiosa de Buenos Aires. Buenos Aires: Biblos, p. 111-118, 2003 a.

- - C Casa de Oración y Beneficencia del Culto Cristiano "Irma de Maresco". In: FORNI, Floreal; MALLIMACI, Fortunato; CÁRDENAS, LUIS. Guía de la Diversidad Religiosa de Buenos Aires. Buenos Aires: Biblos, p. 119-125, 2003b.

DI STEFANO, Roberto; ZANATTA, Loris. Historia de la Iglesia Argentina. Desde la Conquista hasta fines del Siglo XX. Buenos Aires: Grijalbo-Mondadori, 2000.

DURKHEIM, Emile. Las Formas Elementales de la Vida Religiosa. Madrid: Alianza, 1993.

ESCUELA CIENTÍFICA BASILIO. Boletín mensual, Buenos Aires, n. 30, p. 1-4, 1948.

. 50 Años de Vida Institucional. Buenos Aires: Asociación Escuela Científica Basilio, 1967. tífica Basilio, 1968.

. Nuestros Guías Espirituales. Buenos Aires: Asociación Escuela Cien80 Años de Vida Institucional. Buenos Aires: Asociación Escuela Científica Basilio, 1997.

FORNI, Floreal. Nuevos Movimientos Religiosos en Argentina. In: FRIGERIO, Alejandro. Nuevos Movimientos Religiosos y Ciencias Sociales II. Buenos Aires: CEAL, p. 7-23, 1993.

GARCÍA CANCLINI, Néstor. Culturas Hibridas. Estrategias para Entrar y Salir de la Modernidad. México: Sudamericana, 1992. 
- Cultura popular. De la épica al simulacro. In: Quaderns Portàtils, http://www.macba.cat/uploads/20070307/QP_06_Canclini.pdf, 2006.

GOODE, Erich; BEN-YEHUDA, Nachman. Moral Panics: Culture, Politics, and Social Construction. Annual Review of Sociology, n. 20, p. 149-171, 1994. GUTIÉRREZ, Leandro; ROMERO, Luis Alberto. Sectores Populares, Cultura y Política. Buenos Aires en la Entreguerra. Buenos Aires: Siglo XXI, 2007.

LEONE, María Cristina. Un Caso de Religiosidad Popular Urbana: El Culto a la Madre María en Buenos Aires. In:AA.VV. Ocultismo y Espiritismo en la Argentina. Buenos Aires: CEAL, p. 79-88, 1992.

LÉVI-STRAUSS, Claude. Antropología Estructural. Barcelona: Paidós, 1992.

LUDUEÑA, Gustavo Andrés. Cosmología y Epistemología Espiritualista en la Escuela Científica Basilio. Ilu, Revista de Ciencias de las Religiones, Madrid, n. 6, p. 67-77, 2001a.

. Dos experiencias místicas de lo numinoso. Numen. Revista de Estudos e Pesquisa da Religião, Juiz de Fora, n. 6, p. 87-118, 2001b.

nacional en el campo religioso argentino. In: XII Jornadassobre Alternativas Religiosas en América Latina, 2003, San Pablo.

————. ¿De Qué Hablamos Cuando Hablamos de Religión? Experiencia, Identidad y Poder o Hacia una Antropología de lo Religioso. In: $1^{\circ}$ Congreso Latinoamericano de Antropología, 2005, Rosario.

——_- Imagen y Reconstrucción de la Identidad Social en el Espiritismo Argentino. In: FOLLMANN, José Ivo; LOPES, José Rogério. Diversidade religiosa, Imagens e Identidades. Porto Alegre: Armazém, p. 87-112, 2007 a.

- —— L Los benedictinos ¿orar y trabajar? Todo es Historia, año XL, n. 479, p. 44-52, 2007b.

. Persona, Moralidad y EthosReligioso en el Espiritismo Argentino. In:WRIGHT, Pablo. Periferias Sagradas. Antropología de las HeterodoxiasSociorreligiosas en Buenos Aires. Buenos Aires: Biblos, en prensa. 
MARIÑO, Cosme. El Espiritismo en la Argentina. Buenos Aires: Editorial Constancia, 1963.

MÍGUEZ, Daniel; SEMÁN, Pablo. Introducción. Diversidad y recurrencia en las culturas populares actuales. In: Entre santos, cumbias y piquetes. Las culturas populares en la Argentina reciente. Buenos Aires: Biblos, p. 11-32, 2006.

OLMOS, Paola. Confederación Espiritista Argentina. In: FORNI, Floreal; MALLIMACI, Fortunato; CÁRDENAS, Luis. Guía de la Diversidad Religiosa de Buenos Aires. Buenos Aires: Biblos, p. 103-110, 2003.

OTTO, Rudolf. Lo Santo. Lo Racional y lo Irracional en la Idea de Dios. Madrid: Alianza, 1980.

ROMERO, Luis Alberto. Católicos en movimiento: activismo en una parroquia de Buenos Aires, 1935-1946. Estudios Sociales, año VIII, n. 14, p. 89-104, 1998. TURNER, Victor W. El Proceso Ritual. Estructura y Antiestructura. Madrid: Taurus, 1988.

WILLIAMS, Raymond. Marxismo y Literatura. Barcelona: Península, 1980. 